\title{
The Effect of Leadership Behavior on Project Success among Kuantan Malaysian Construction Industries
}

\author{
M.H. Yusoff ${ }^{\mathrm{a}}$, A.Q. Adeleke* ${ }^{\mathrm{a} *}$, A.I. Ismail ${ }^{\mathrm{b}}$

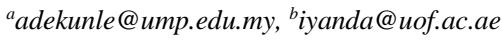 \\ ${ }^{a}$ Faculty of Industrial Management, Universiti Malaysia Pahang, Lebuhraya Tun Razak, 26300 Gambang, Pahang, Malaysia \\ ${ }^{b}$ College of Business Administration, University of Fujairah, UAE
}

\begin{abstract}
Leadership behaviors in modern industries especially the construction industry have become a crucial factor in determining the success of the construction project. The unsuitable culture can have an impact on the organization itself, based on the project management perspective. As for the construction, it is likely to face different problems such as project failure, over budget, delay in terms of scheduling, ineffective management and dissatisfaction of the clients. These problems above show how challenging the construction project is. There are a few characteristics that shows that the construction industry is different from other industries. This is why understanding the leadership behavior is crucial because of the differences that will be faced. To address these issues above, this study aims 1) to determine the influence of visioning on project success among Kuantan Malaysian construction industry; and 2) to determine the influence of coaching on project success among Kuantan Malaysian construction industry. The researcher collected data from 107 respondents among construction companies in Kuantan. In this research, the PLS-SEM technique was used to analyze both the measurement and structural models. The result shows that there is a significant positive relationship between leadership behavior and project success among the construction industry in Pahang, Malaysia. Implications for practice and future research were also discussed.
\end{abstract}

Keywords: Leadership behavior, visioning, Coaching, Project Success, Project Manager

\section{Introduction}

Leadership means authority in the widest sense of the word and not only the ability to bear the stick, but organizational skill requires the personal attributes of leaders (Tsai, 2011). Additionally, leadership skills are relevant factors in carrying out successful project formation. It is the responsibility of the project manager to ensure that project success have traditionally been described as a project that meet its objectives under budget and schedule (Siles, 2008). Cost management is also seen to be one of the most essential to the success of a project. The construction industries in Malaysia have a major impact on the country's economic development. The sector has contributed 3-5\% to the country's GDP during the last 20 years (CIDB Malaysia, 2009). Hence the presence of the construction industry plays a major role in promoting a healthy lifestyle and standard of living in the country.

Previous research has shown that there is a major difficulty in providing effective leadership due to failure to agree on the practical and consequential management categories (Yukl, 2012) and the consequences from the studies that used different behavioral categories are very difficult to differentiate and combine. Ineffective management is one major factor to bring about a project failure. Furthermore, the issue is the inability to differentiate leadership style and correlation that may lead to intense arrangements in the project situation regarding projects that have failed and may antagonize the implementation of key organizational goals and vision. According to Liphadzi, Aigbavboa and Thwala (2015), in the construction industry context in South Africa, planning and the issue of budget are not the main problem but they opined that the most problematic factor in the country's construction industry is leadership.

This study aimed to determine the influence of visioning on project success among Kuantan Malaysian construction industry and to determine the influence of coaching on project success among Kuantan Malaysian construction industry. Many parties in Malaysia may take advantage of this study's findings. This study will be of advantage to researchers to find more benefits in project success and leadership behavior and also help 
construction companies to find out which factors affect the effect of leadership behaviors, both in public and private construction companies on project success in Kuantan Malaysia.

\section{Literature Review}

\subsection{Overview of Malaysian Construction Industries}

Malaysians were involved in the building industries after the era of independence in 1957. Malaysia has been involved in a wide range of sectors, including mining, forestry, tourism and buildings. Construction industries are among the world's biggest and riskiest, but several companies in Malaysia have entered the building industry. Malaysia also has a large, prolific industry in the building industry. The Malaysian budget report shows the revenue of RM 7,248 million in 2004 for the building industry, RM 7,168 million in 2005 and RM 7,350 million in 2006. These values show how relevant and heavy the construction industry has contributed to the growth of the Malaysian economy.

The Malaysian construction industry reaches the greatest potential in 1995 with the shift of property development by $15.8 \%$ for new buildings and $34.1 \%$ for an existing building. In addition, transfer development reached $11.7 \%$ for a new and existing building, which go over 150,000 units with a total of more than RM15.8 billion. According to the Construction Industry Development Board of Malaysia (2019), it was reported that the construction industry will be prioritized by the government as one of the main keys to the nation's economic growth in the 2020 budget.

Additionally, CIDB said that RM1 billion guaranteed to committed private equity funds to spend in Malaysia consortiums would support the involvement of more Malaysian companies outside of Malaysia construction projects. Furthermore, the government also focuses on Incentivizing Technical and Vocational Education and Training (TVET) initiation which tends to involve more local teens to enroll in TVET courses, majorly in the construction industry (Bernama, 2019). Consequently, according to the Malaysian Ministry of Finance, it was reported that the construction industry is supposed to increase by $3.7 \%$ in 2020 , rising from the $1.7 \%$ forecast seen in 2019. The construction industry in Malaysia would be value at around RM70 billion and the reason why the construction industry grows is because of the mega project which is the East Coast Rail Link (ECRL) and it was estimated that this project will be completed in 2026 (Brown, 2019).

\subsection{Conceptual Framework}

This analysis shall be carried out using the model that is clearly described as an independent variable and a dependent variable. For this study, the independent variable consists of leadership behaviour (visioning and coaching) and the dependent variable is project success based on the conceptual context. The framework thus shows how the independent variable is expected to influence the dependent variable or not in the final results of this study. Therefore, the relationship between leadership behaviour and project success can then be related to the project success in Pahang, Malaysian construction projects.

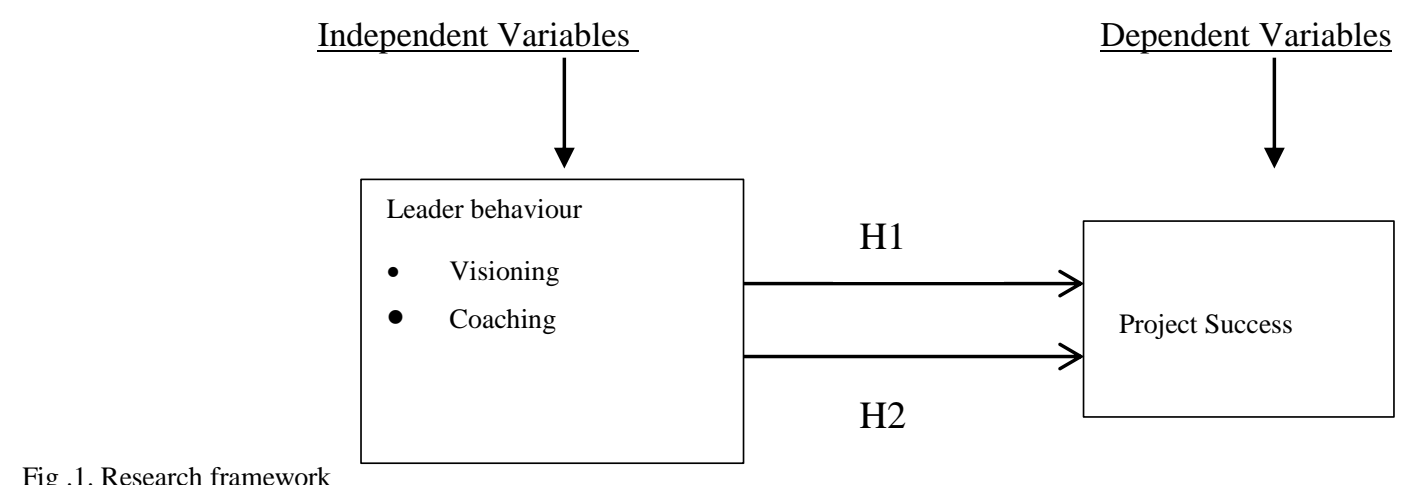




\subsection{Relationship between visioning and project success}

The practical way for leaders to develop a commitment to new approaches and projects is to express a clear and compelling vision of what the work unit or company should achieve. A vision can become more inspirational and motivating when it is important to followers ' standards, goals, expectations and communicated in a vibrant, and emotional language (Yukl, 2012). It is more likely to be taken by team or company leaders if the leader can create a trust that leader he or she can succeed. However, an inspiring dream based on mistaken premises and wishful thinking can draw focus away from successful approaches that are more likely to lead to project success (Mumford, Gaddis, and Strange, 2002). Pursuing a risky and impossible dream regularly is a significant explanation for severe declines in results in organizations with a competent leader (Finkelstein, 2003; Iyanda et al., 2020).

Visioning is a process, not a moment, but a clear empirical and linear process to a given outcome. Rather it is a cycle that goes up and down, sometimes feeling like two steps forward and one step backward, sometimes even more steps backward. Many times project management are step, rather than moves in a completely different direction (Nooyen et al., 2014). Usually, the cycle has moments of frustration as the initial task frame can prove to be too limiting or the first innovative explorations may give no results. Good visioning has key features frequently and innovative leadership means trying to build as many of those conditions as possible. The leader communicates the vision and helps the team to clarify its goals because having a compelling vision and a detailed plan is important (Katzenbach and Smith 2003).

Good leadership is so crucial to express the belief that there is always a way forward, and that's what the project manager is trying to find out on how to push the company forward (Gordon, 2017). True leaders have a dream, that is, they can see the future as it is and imagine a future that will culminate from the present. An optimistic leader can predict the future and live in the moment. A vision is a target which leaders should invest and guide their time and resources toward. Leaders share a vision and a path that workers wish to share and pursue. The vision of leadership is not limited to an organizational written statement of mission and declaration of vision. It's well illustrated in the corporate leaders behaviour, principles and values. Building and maintaining favourable relationships with subordinates, superiors and outsiders who can provide knowledge, resources and political support is important to most leaders (Yukl, 2012).

According to Myatt (2012), leaders without vision are unable to succeed in life, and they operate in a normal and repetitive way. To leaders, vision is not imagination; instead, it is a reality that is yet to come into practice. A leader must extend extra efforts to achieve a vision, and have a strong faith and commitment to realize the vision. Vision acts as an internal force that propels a leader to take action. Despite numerous challenges and difficulties, the clear presence of a dream makes a leader progressive. Vision is a bond that unites individuals with a common goal into a team and the project managers must always have the expertise to guide the teamwork. Project managers inside the internal organization have to direct their subordinates, a circumstance that needs them to possess strong leadership skills required to promote the productive achievement of project goals by the employees (Sunindijo, Hadikusumo, and Ogunlana, 2007). Based on the aforementioned discourse, we, therefore, hypothesized that:

Hypothesis 1: There is a significant relationship between visioning and project success.

\subsection{Relationship between coaching and project success}

Coaching is the method of modifying behaviour, whether the aims are technical or personal, and improve the effective accomplishment of objectives. Mosca (2010), identified coaching as a key management process, where the manager focuses on creating, evaluating, advising, or coaching employees to improve the capacity to achieve strategic organizational goals. The coaching practice is in addition to conventional preparing, coordinating, guiding, staff managing, and motivating and regulating management practices.

Also, interpersonal skills development, strategic thinking, conflict management, style management, leadership, communication and adaptability or flexibility include the traditional coaching areas (Bono et al., 2009; Ismail et al., 2020). So, when the performance is poor or the team members do not have the experience, the leader must accomplish the mission efficiently. Generally, project managers work closely with project partners and see opportunities for growth that a resource manager does not have access to. For instance, the project manager should step in to offer solutions to disputes, or work with the group to enhance their 
communication, if a team member has problems interacting and the interactions are negative for a team member. A project manager's core skills are evident in particular circumstances in which coaching will support team success and the project manager is responsible for improving this skill as part of his professional development program.

Therefore, since successful coaching would turn outstanding team members into high-performance contributors to this project, coaching style should be utilized as a part of a project manager's qualities. In addition, coaching also helps inspire the manager to take care of the performance of the team (Woods, 2011). Furthermore, communicating and creating team cohesion can be strengthened by positive coaching activities and is involved in project and organization's progress. We, therefore, hypothesized that;

Hypothesis 2: There is a significant relationship between coaching and project success.

\subsection{Methodology}

This study adopted a descriptive research design and quantitative approach in gathering relevant information on the relationship between independent (visioning and coaching) variables and the dependent variable (project success). There are three methods employed in this analysis to assess the effect of leadership on project success in the construction industries. The framework is the first tool. The questionnaire is recommended as the correct survey tool for all research instruments (Adeleke et al., 2020). The items from previous research were analyzed to create questionnaires to ensure that all variables are accurately calculated. The data will thus be obtained by using a questionnaire for this study from the construction industries in Kuantan, Pahang. This work then uses a cross-sectional approach. Cross-sectional Survey-based research is defined as data collected from people that have a similar charactereristic, almost the same knowledge of the management of the construction industry and the collaborative team.

\subsection{Implementation of Design}

In addition, the Likert scaling was used to calculate all variables examined in the research setting for this study. As a result, the respondent was measured under categories "Very High=5," "High=4," "Medium=3," "Low=2" and "Very Low=1." This method was used to get respondents 'input.

Table 1: Summary of the survey instrument in the questionnaire

\begin{tabular}{llll}
\hline Section & Description & Variable & No. of Item \\
\hline 1 & Demographic & - & 8 \\
2 & Visioning & IV's & 9 \\
3 & Coaching & IV's & 10 \\
4 & Project Success & DV's & 10 \\
\hline \multicolumn{2}{r}{ Total 37 } \\
\hline
\end{tabular}

\subsection{Result and Discussions}

\subsection{Data Collection and Sample}

160 copies of the questionnaire were given to the senior staffs of Pahang construction companies in Kuantan. The number of copies of the completed and returned questionnaire amounted to 107, which is the same as the required sample size. For this research, Table 2 shows a summary of the demographic characteristics of the respondents. 
Table 2: Summary of Demographic Scales of Respondents

\begin{tabular}{|c|c|c|c|}
\hline Type & Item & Frequency (n) & Percentage (\%) \\
\hline \multirow[t]{6}{*}{ Position } & Contract Manager & 7 & 6.54 \\
\hline & Project Manager & 17 & 15.89 \\
\hline & Architect & 10 & 9.35 \\
\hline & Engineer & 15 & 14.02 \\
\hline & Contractor & 19 & 17.76 \\
\hline & Other & 39 & 36.44 \\
\hline \multirow[t]{4}{*}{ Working Experience } & 1-3 Years & 42 & 39.25 \\
\hline & 4-6 Years & 39 & 36.45 \\
\hline & 7-9 Years & 11 & 10.28 \\
\hline & $>10$ Years & 15 & 14.02 \\
\hline \multirow[t]{2}{*}{ Gender } & Male & 63 & 58.88 \\
\hline & Female & 44 & 41.12 \\
\hline \multirow[t]{4}{*}{ Type Of Project } & Apartment buildings & 57 & 53.27 \\
\hline & Bridges & 15 & 14.02 \\
\hline & Roads & 26 & 24.3 \\
\hline & Others & 9 & 8.41 \\
\hline \multirow[t]{2}{*}{ Company Ownership } & Local & 95 & 88.79 \\
\hline & National & 11 & 11.21 \\
\hline \multirow[t]{4}{*}{$\begin{array}{l}\text { Company } \\
\text { Location }\end{array}$} & Local Market Area & 41 & 38.32 \\
\hline & Within Few States Regional & 21 & 19.63 \\
\hline & Across Malaysia & 38 & 35.51 \\
\hline & International Markets & 7 & 6.54 \\
\hline
\end{tabular}




\begin{tabular}{llll} 
Company Existence & 1 -3years & 10 & 9.35 \\
& 4-6years & 22 & 20.56 \\
& 7-9years & 19 & 17.76 \\
& $>1$ yyears & 56 & 52.34 \\
& & & \\
No. Of Full-time & & & \\
Employee & $0-50$ & 46 & 42.99 \\
& $50-100$ & 26 & 24.3 \\
& $100-150$ & 14 & 13.08 \\
& $150-200$ & 2 & 1.87 \\
& $>200$ & 19 & 17.76 \\
\hline
\end{tabular}

\subsection{Measurement Model}

The method used to monitor and calculate the inner and outer models was Partial Least Square Structure Equation Modelling (PLS-SEM). Figure 2 shows the model of this research with the structural dimensions (Azman and Adeleke, 2018).

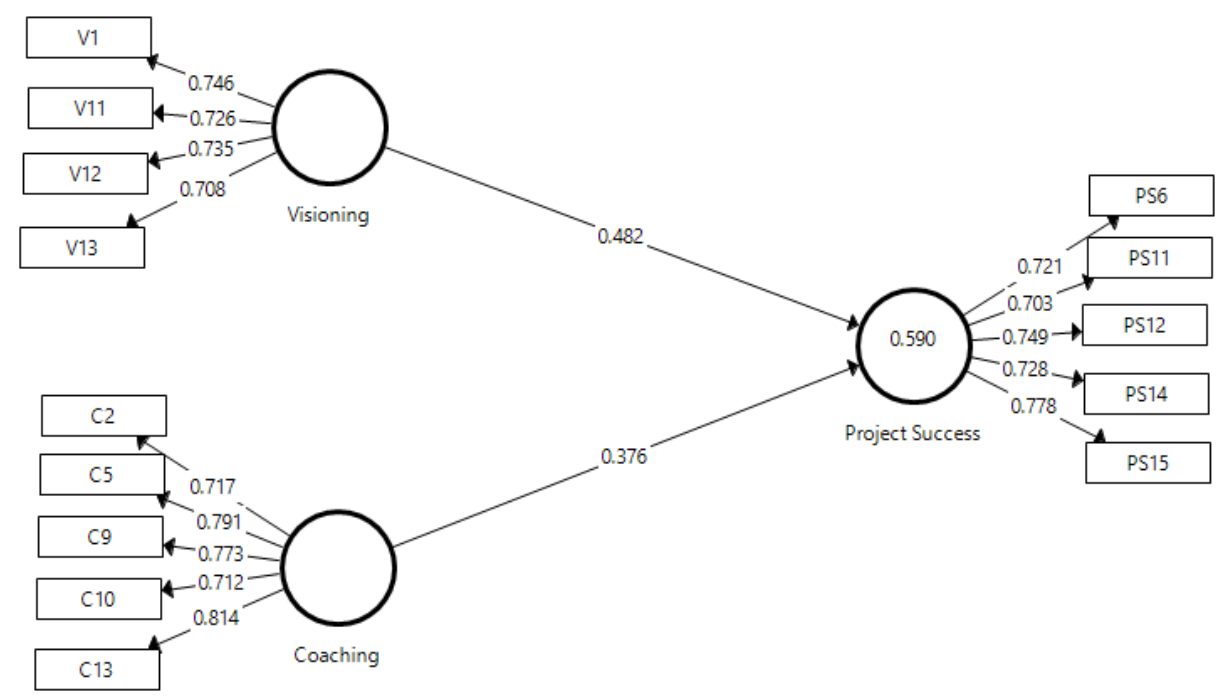

Fig .2. Measurement Model

Convergent validity can be justified as the degree to which a bunch of variables are converged to measure a certain concept. The loadings of all items were tested and those items which have values more than 0.5 were accepted. Composite reliability is the degree to which a group of items shows latent constructs of the model (Kanimoli et al., 2020).

Table 3: Descriptive Statistic and Normality Assessment Criteria

\begin{tabular}{lllllll}
\hline Construct & Min & Max & Mean & Std. Deviation & Kurtosis \\
\hline V & 2 & 5 & 4.11 & 0.59 & 0.42 & 0.21 \\
C & 1 & 5 & 4.08 & 0.63 & 0.15 & -0.22 \\
PS & 2 & 5 & 4.12 & 0.60 & 0.17 \\
\hline
\end{tabular}


The result was evaluated using the descriptive analysis to derive the mean value and the standard deviation. The mean is determined by the sum of all values, divided by the number of values. Skewness is a test of the symmetry of the distribution. It has been shown that skewness and kurtosis are independent variables and dependent variables. The independent variable is leadership behaviour, while the dependent variable is project success. Then, the value of Composite Reliability (CR) and Average Variance Extracted (AVE) are shown in Table 3 below (Omer and Adeleke, 2019).

Table 4: Convergent Validity Analysis

\begin{tabular}{llllll}
\hline Construct & Item Code & Outer Loading & AVE & CR & Cronbach's Alpha \\
\hline Visioning & V1 & 0.746 & 0.531 & 0.819 & 0.707 \\
& V11 & 0.726 & & & \\
& V12 & 0.735 & & & \\
Coaching & V13 & 0.708 & & 0.874 & \\
& C10 & 0.712 & 0.581 & & \\
& C13 & 0.814 & & \\
& C2 & 0.717 & & \\
Project & C5 & 0.791 & & \\
success & C9 & 0.773 & & & \\
& PS11 & 0.703 & & & \\
& PS12 & 0.749 & & & \\
& PS14 & 0.728 & & & \\
& PS15 & 0.778 & & & \\
& PS6 & 0.721 & & & \\
\hline
\end{tabular}

In addition, discriminant validity is significant for the construction of the outer model. The discriminant validity had to be ascertain before looking into the path analysis. Discriminant validity indicates the degree to which the objects are differentiated from the constructs (Subani et al., 2020). It means that items that are used in various constructs do not overlap.

As illustrated in Table 4, the square root of AVE for all the constructs was used to replace the diagonal elements on the correlation matrix. The discriminant validity of the outer model for this analysis was confirmed where the diagonal elements in the table were higher than the other column and row elements in which they were placed. The discriminant validity of this study was therefore supported by the external model. As indicated in Table 5, satisfactory discriminant validity was also achieved when the value representing the square root of the AVE (appearing bold on the diagonal) were all loaded above the recommended threshold value of 0.5 and greater than the off-diagonal correlations (Taofeeq et al., 2019).

Table 5. Discriminant Validity: Fornell and Larcker Criterion

\begin{tabular}{llll}
\hline & C & PS & V \\
\hline Coaching & $\mathbf{0 . 7 6 3}$ & & \\
PS & 0.663 & $\mathbf{0 . 7 3 6}$ & \\
V & 0.594 & 0.706 & $\mathbf{0 . 7 2 9}$
\end{tabular}

Note: Diagonal values are square-root of AVE, off diagonal values are correlation coefficient

The next process after confirming the goodness of the outer model was to investigate the relationships that were hypothesized in the study. PLS Algorithm was run to investigate the hypothesized model through Smart PLS. The path coefficient was gained through running PLS Algorithm, which is shown in Table 6 below with proposed hypotheses. The results showed that coaching $(\mathrm{C})$ variable has a significant positive relationship on project success $(\beta=0.376, \mathrm{t}=4.927, \mathrm{p}=0.000)$. On the other hand, visioning $(\mathrm{V})$ also has a positive 
relationship on project success $(\beta=0.482, \mathrm{t}=5.918, \mathrm{p}=0.000)$. The two independent variables have a positive and significant relationship on project success among Kuantan Malaysian construction industries. Thus, accepting the two aforementioned hypotheses (Malik and Adeleke, 2018).

Table 6: Results of the Inner Structural Model

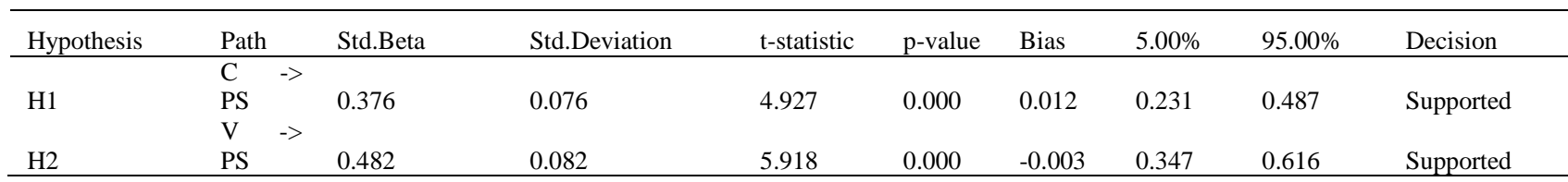

Table 7: R square table

\begin{tabular}{ll}
\hline & R Square \\
\hline PS & 0.590 \\
\hline
\end{tabular}

The model is evaluated according to the value of the decision coefficient $\mathrm{R}^{2}$. The rule of thumb appropriate for the $\mathrm{R}^{2}$ result is that when the value is between 0.25 and 0.49 it is considered to be weak, when it is between 0.50 and 0.74 it is considered moderate and 0.75 above are strong. Thus $\mathrm{R}^{2}, 0.590$ is considered to be moderate to the thumb rule (Panda et al., 2020).

Table 8 . Value of $\mathrm{f}^{2}$

\begin{tabular}{|c|c|c|c|c|}
\hline & $\mathrm{C}$ & PS & V & Effect Size \\
\hline $\mathrm{C}$ & & 0.223 & & Large \\
\hline \multicolumn{5}{|c|}{ PS } \\
\hline V & & 0.367 & & Large \\
\hline
\end{tabular}

In particular, based on the checked $\mathrm{Q}^{2}$ statistic of 0.294 in table 9 , the predictive validity of the model is shown for the endogenous latent variable of this analysis, larger than zero (Ismayana and Adeleke, 2020).

Table 9. Value of $\mathrm{Q}^{2}$

\begin{tabular}{l}
\hline $\mathrm{Q}^{2}(=1-\mathrm{SSE} / \mathrm{SSO})$ \\
\hline 0.294
\end{tabular}

\subsection{Discussion and Conclusion}

The aim of this study was to examine the effect of leadership behaviour on project success among Kuantan Malaysian construction industries. It provides organizations and academicians with the tools and knowledge to further enhance the impact of leadership actions on project success. In several leading research literature, a significant objective was to detect aspects of behaviour, which clarify the leadership's impact on their results (Samsudin et al., 2020). Issues such as time overruns, cost overruns, building efficiency and safety during the building process, which are dominant in the construction industry for a long time, are difficult to overcome due to a variety of factors like leadership quality. Solving these problems will boost the competitiveness of the industry (Ain and Rahman, 2016). For this reason, this study focused on the influence of effective leadership behaviour on project success among Kuantan Malaysian construction industries.

The first objective of this study was to evaluate the relationship between visioning and project success among Kuantan Malaysian Construction industries. From the result, it was shown that visioning has a positive 
and significant relationship with project success. In addition to that, the results of Cronbach Alpha showed that the CA for the independent variable (visioning) was 0.707 and the dependent variable (project success) was 0.789. The value of Cronbach alpha is appropriate in this study because, with this sample, it shows a very good internal accuracy reliability per scale and is above 0.7 (Adeleke and Rahman, 2018). In order to complete an effective construction project, good construction managers should be able to identify project power, weakness, potential, and danger. This increases organizations' benefit because there is less or no work repetition. In addition, proactive leaders strive to create new opportunities rather than just project completion and healthy leaders with ethical actions will also boost their professional images (Rahman, et al, 2016).

The second objective of this study was to assess the relationship between coaching and project success among Kuantan Malaysian Construction industries. The findings also show that coaching has strong ties to the project's success. Furthermore, the results showed that the Cronbach Alpha for the independent variable (coaching) was 0.819 and the project success was 0.789. For this analysis, the Cronbach Alpha is adequate because the internal exactness of the sample by scale is high and the value is above 0.7 (Palant et al., 2007). Coaching is a form of personal development carried out in the changing process with the help of a coach who leads and supports the individual. The construction company also succeeds in coaching when the employee is coached, as workers become more acquainted with the project and achieve success.

\subsection{Implication}

This examine the effect of leadership behaviour on project success among Kuantan Malaysian construction industries. In different sectors, such as the public utilities, telecommunications, hospital and even government departments, a number of related studies have been carried out. Many related studies have been carried out to show that successful management has a better or legitimate outcome for project success. This research was also expanded to cover the reliability of the IV's and DV in this study by parties interested in the construction industry, which will boost research stability. Furthermore, this research is worthwhile and adds importance to the construction industry in Malaysia.

Project success studies are not only necessary for the academic sector, but also for the employer, who in every construction industry has needed success. Similarly, in the construction industry, the promising results towards enhancing the project success have become the key driver over the last few years. In addition, it will help the industry optimize its benefit objectives. In this study, parties in the building/construction industry will use the result of this study to improve their management strategy. The studies of Emmitt and Gorse (2007) revealed that project managers must possess the vision and coaching skills in order to handle construction projects successfully.

Lack of vision is also one of the problems in the building sector that could lead to significant production problems and raise the level of failure. Leadership conduct is important to all building parties in order to minimize construction project failure. This study is therefore important to analyse the influence of leadership actions on the performance of projects in the Kuantan construction industry in Malaysia.

\subsection{Research Limitation}

This study was carried out in Kuantan only in the construction industry. In order to obtain more reliable outcomes, further study should include a broader nationality group and the findings will provide stability for this study. In addition, only employees in the construction industry are entitled to the data collected for this report. It can only be used for evaluating effective management actions in the construction industry and not for other sectors, such as oil and gas, and banking.

\section{References}

Adeleke, A. Q., Nawi, M. N. M., \& Abd-Karim, S. B. (2020). Where are we? the level of risk management in Malaysian construction industries. Int. J Sup. Chain. Mgt Vol, 9(1), 527.

Adeleke, A. Q., \& Rahman, N. F. A. (2018). The Relationship between Effective Communication and Construction Risk Management among Kuantan Malaysian Construction Industries. Journal of Advanced Research in Applied Sciences and Engineering Technology, 10(1), 1824.

Azman, N. A. S. M., \& Adeleke, A. Q. (2018). Effect of Time Overruns on Apartment 
Building among Kuantan Malaysian Construction Industries. Journal of Advanced Research in Applied Sciences and Engineering Technology, $10(1), 41,47$.

Bono, J. E., Purvanova, R. K., Towler, A. J., and Peterson, D. B. (2009). A Survey of Executive Coaching Practices. Personnel Psychology, 62(2), 361-404. doi:10.1111/j.1744-6570.2009.01142.X

Brown, A. (2019). Malaysian construction to grow 3.7\% in 2020. Finkelstein, S. (2003). Why Smart Executives Fail.

Ismayana, M. P., \& Adeleke, A. Q. (2020). The Influence of Organizational Culture on Construction Risk Management among Kuantan Malaysian Construction Industry: A Partial Least Square Structural Equation Modeling Approach. Social Science and Humanities Journal, 1693-1704.

Ismail, A. I., Abdul-Majid, A. H., Ameen, A., Raza, S., \& Tomilayo Akindele, I. Y. I. O. L. A. (2020). Using employee creativity to unpack the 'black box'in the high-performance work system (HPWS)-firm performance nexus. International Journal of Innovation Management, 24(06), 2050052.

Iyanda Ismail, A., Awawdeh, A., Al-Hiyari, A., \& Isiaka Jimba, K. (2020). Moderating Effects of Management Philosophy on High-Performance Work Practices-Firm Performance Relationship. Journal of African Business, 1-15.

Joseph B. Mosca, A. F., John Buzza. (2010). Coaching To Win: A Systematic Approach To Achieving Productivity Through Coaching.

Kanimoli, A., Adeleke, A. Q., \& Taiwo, T. T. (2020). ORGANIZATIONAL STRUCTURE INFLUENCE ON CONSTRUCTION WASTE MANAGEMENT AMONG PENANG MALAYSIAN CONSTRUCTION INDUSTRY: AN APPROACH VIA PARTIAL LEAST SQUARE STRUCTURAL EQUATION MODELING. Journal Homepage: https://www. jobmer. org, 4(1).

Malik, N. S. A., \& Adeleke, A. Q. (2018). The Effect of Organizational Culture on Material Risk among Malaysian Construction Industries. Journal of Advanced Research in Applied Sciences and Engineering Technology, 10 (1), 34, 40.

Michael D. Mumford, G. M. S., Blaine Gaddis, Jill M. Strange. (2002). Leading creative people: Orchestrating expertise and relationships.

Omer, M. S., \& Adeleke, A. (2019). Systematic Critical Review of Risk Management in Malaysian Construction Companies. Journal of Humanities and Social Sciences Studies (JHSSS) Vol, 1.

Samsudin, N. S. A., Adeleke, A. Q., \& Ajibike, W. A. (2020). Effects of Contractors' Delay Factors on Building Project Performance Among Kuantan Malaysian Construction Industry. Social Science and Humanities Journal, 1705-1715.

Subani, N. A., Adeleke, A. Q., \& Bamgbade, J. A. (2020). The Role of Organizational Culture on Sustainable Construction among Malacca Malaysian Construction Industry: A Partial Least Square Approach. Social Science and Humanities Journal, 1681-1692.

Sunindijo, R. Y., Hadikusumo, B. H., and Ogunlana, S. (2007). Emotional Intelligence and Leadership Styles in Construction Project Management. Journal of Management in Engineering, 23(4), 166-170. doi:10.1061/(asce)0742-597x(2007)23:4(166)

Tsai, Y. (2011). Relationship between organizational culture, leadership behavior and job satisfaction. BMC Health Serv Res, 11, 98. doi:10.1186/1472-6963-11-98

Woods, J. A. (2011). The project manager as team coach: a plan for success.

Yukl, G. (2012). Effective Leadership Behavior: What We Know and What Questions Need More Attention. Academy of Management Perspectives, 26(4), 66-85. doi:10.5465/amp.2012.0088 